\title{
Use of fiberoductoscopy for the management of pathological nipple discharge: ten years follow up of a single center in China
}

\author{
Chao Zhang, Jie Li, Hongchuan Jiang, Mengxin Li \\ Breast Cancer Department, Beijing Chaoyang Hospital, Beijing, China \\ Contributions: (I) Conception and design: C Zhang; (II) Administrative support: J Li, H Jiang; (III) Provision of study materials or patients: C Zhang; \\ (IV) Collection and assembly of data: M Li; (V) Data analysis and interpretation: C Zhang; (VI) Manuscript writing: All authors; (VII) Final approval \\ of manuscript: All authors. \\ Correspondence to: Chao Zhang. Beijing Chaoyang Hospital, Beijing, China. Email: Zhchao601@icloud.com.
}

\begin{abstract}
Background: Pathological nipple discharge (PND) is usually associated with benign intraductal papilloma, which has a higher malignant rate than other benign tumors in most cases. Fiberoductoscopy (FDS) is an alternative possibility in diagnostic and finding lesions in PND patients. Previously, the bloody discharge was presumed to show papilloma or breast cancer. However, as we started using FDS, papilloma or cancer also can be found in the cases with a transparent or yellow discharge. This study investigated the value of FDS for the diagnosis and locating of intraductal lesions in cases with nipple discharge.

Methods: A retrospective analysis of 3,696 cases that initially presented with pathologic nipple discharge was performed. There were 4,456 FDSs performed, and the correlations between the FDS findings for distinct types of lesions and the pathological diagnosis were determined.

Results: Among the 2,816 cases of elevated lesions, FDS confirmed 1,933 cases of intraductal papilloma, 584 cases of intraductal papillomatosis, and 299 cases of intraductal carcinoma. Among the 880 cases of nonelevated lesions, FDS confirmed 380 cases of duct dilation, 350 cases of duct inflammation, 136 cases of duct dilation and inflammation, and 14 cases of ductal carcinoma in situ (DCIS). All patients followed up 3 months to 12 years. There were 241 DCIS in total, and 8 cases had local recurrence, 2 cases had metastasis. Invasive ductal carcinoma, 41 cases, 3 had recurrence and 3 had metastases, and 1 for death. Invasive lobular carcinoma 23 cases, recurrence 2 cases, metastasis 1 case.

Conclusions: FDS has a high positive predictive rate and correlates well with the results of the pathological examination. The advantage of FDS is that it can observe the lesions, increasing the detection rate of early stage breast cancer, simple to operate, low cost, and no need for the appointment, appropriate for Chinese conditions.
\end{abstract}

Keywords: Fiberoductoscopy (FDS); nipple discharge; mammary duct lesion; ductoscopy

Submitted Sep 07, 2020. Accepted for publication Oct 29, 2020.

doi: $10.21037 /$ gs-20-738

View this article at: http://dx.doi.org/10.21037/gs-20-738

\section{Introduction}

Pathologic nipple discharge (PND) is 1 of the 3 most common symptoms of breast disease, and its incidence is $3 \%$ to $8 \%$. Intraductal papilloma has a higher malignant rate than another benign breast tumor (1-3). Mammography and B-ultrasound are the most common methods for PND screening in China, which is cheap and safe. Sometimes, magnetic resonance imaging (MRI) and cytological analysis of nipple secretion or duct lavage fluid may also be performed. Sometimes, if the mammography and B-scan ultrasound results are negative, the value of MRI, whose high cost cannot be afforded by most Chinese people would also be limited. However, the sensitivity of ductography and cytological analysis of nipple secretion or duct lavage fluid is low for detecting potential lesions (4-8).

Previously, the bloody discharge was supposed to show 
the papilloma or breast cancer. However, as we started using fiberoductoscopy (FDS), papilloma or early stage cancer also is found in the cases with a transparent or yellow discharge. Also, no consensus has been set up on detection methods for PND. FDS is an endoscopic method for diagnosing intraductal micro-lesions with PND but no lumps, and it enables a visual examination of the duct epithelium (7-11). However, researchers are still debating the value of FDS. Some studies have proved significant correlations between FDS and pathological examination findings $(12,13)$, but other studies have observed positive correlations for papilloma only (14-16).

We present the following article in accordance with the STROBE reporting checklist (available at http://dx.doi. org/10.21037/gs-20-738).

\section{Methods}

Inclusion criteria: for all patients with pathological nipple discharge (PND) during non-lactation period, doctors informed them of the operation and risk of ductoscopy. FDSs were done to all the patients who agreed to. Patients with positive result were given location and surgery. All The results were included in this study. PND patients who underwent FDS at Chaoyang Hospital, Capital Medical University between January 2002 and December 2018 were included in this study. An in-depth discussion about the risks and benefits of the procedure was followed by obtaining informed written consent for patients to undergo FDS. All patients agreed to follow the study schedule and undergo biopsies after FDS. The Ethical Committees approved this project of Beijing Chaoyang Hospital. The study conformed to the provisions of the Declaration of Helsinki (as revised in 2013).

\section{Instrument}

A breast duct endoscope (Blade) and a computerized image acquisition system were used, and the breast localization needles were acquired from Biopsy (USA).

\section{Procedure}

The procedure was performed while the patient was seated. After routine disinfection and draping, a $0.45 \mathrm{~mm}$ needle without a tip was inserted into the duct with discharge (Figure 1 ), $0.2 \mathrm{~mL}$ of $0.5 \%$ tetracaine was injected for topical anesthesia, and a duct dilator was used to dilate the duct. Then, the outer cannula and then the endoscope was inserted into the duct, and a small amount of air was injected to keep the duct open (Figure 1). The endoscope was advanced along the duct to the lesion for assessing target lesions and endoscope depth while examining the duct branches (Figure 1). The shape and location of the target duct were recorded. Then, the endoscope was removed, and any air and fluid in the duct were removed. The nipple was then disinfected, and the patient was instructed not to shower for 24 hours. Five skilled physicians performed the procedure.

\section{Localization}

The endoscope and cannula were advanced to near the target lesion under direct visualization. After the depth was recorded, the endoscope was withdrawn, but the cannula was left in place. A breast localization needle was then advanced to the same depth, and the tail and needle were pushed to flip open the U-shaped tip of the localization needle to secure the target lesion. Subsequently, the tail was withdrawn along the duct to the outside of the nipple, and then the cannula of the localization needle and the cannula of the endoscope were removed. After that, the site was covered with sterile gauze. During the operation, the cannula of the localization needle was advanced to the same depth along the tail, and both the target duct and surrounding breast tissue (approximately $2 \mathrm{~cm}$ ) were removed. The U-shaped tip can be observed at the site of the elevated lesion in Figure 1.

\section{FDS-based diagnostic classification criteria}

According to the FDS classification criteria developed by Professor Hongchuan Jiang (17), non-elevated lesions were classified as 1 of 4 types (Figure 2): duct dilation (type I, Figure $2 C, D$ ), duct inflammation (type II, Figure $2 E$ ), duct dilatation and inflammation (type III, Figure $2 F$ ), and intraductal carcinoma (type IV, Figure 2G). Elevated lesions were classified as one of the three types: intraductal papilloma (type I), intraductal papillomatosis (type II), and intraductal carcinoma [type III; ductal carcinoma in situ (DCIS) and invasive ductal carcinoma].

\section{Pathological diagnosis}

After routine iodine and ethanol disinfection and draping, the cannula was reinserted into the target duct along the 

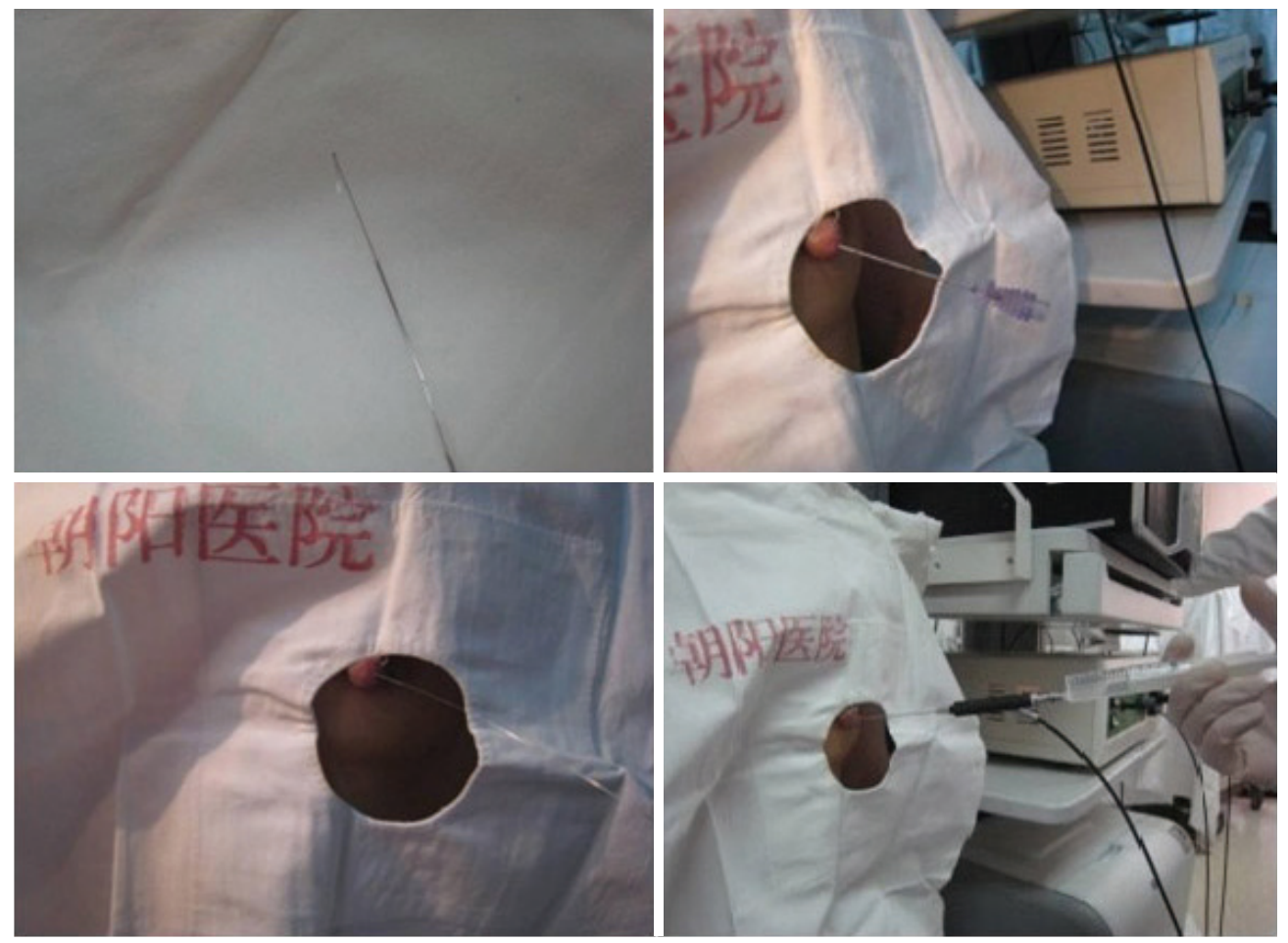

Figure 1 Procedure of FDS. FDS, fiberoductoscopy.

tail. After the cannula position, an incision was made following the areola in the proper quadrant. Later, a skin incision was made, a flap was separated, and the breast tissue was dissected. The target duct was found for the position of the localization wire, entirely removed, and then ligated. The specimen was sent for pathological examination, and the incision site was sutured correctly, followed by the application of the local pressuring dressing.

\section{Statistical analysis}

SPSS v21.0 was used for statistical analysis. The $\chi^{2}$ test was performed to analyze the data, and the kappa concordance test was performed to compare the FDS findings and pathological diagnosis. $\mathrm{P}<0.05$ was considered statistically significant.

\section{Follow up}

Followed up by telephone or outpatient each year, benign cases did a regular blood test, breast b-type ultrasound, mammography, and the malignant case did tumor, marker blood test, chest X-ray, head CT scan, ultrasound for breast and abdomen, bone scans to test metastasis and recurrence.

\section{Results}

Three thousand six hundred ninety-six patients $(4,456$ FDSs) were included in this study. The patients were between the ages of 14 and 89 , with a mean age of $40.62 \pm 9.81$ (median: 40). According to the FDS findings, the lesions were classified as elevated or non-elevated, with no significant between-group differences in the typical characteristics of the patients $(\mathrm{P}>0.05)$. However, significant between-group differences were observed in the color and properties of the discharge $(\mathrm{P}<0.05)$, but no significant between-group difference was observed in the distribution of the lesions $(\mathrm{P}>0.05)$ (Table 1).

FDS confirmed 2,816 cases of elevated lesions, including 1,933 cases of intraductal papilloma, 584 cases of intraductal papillomatosis, and 299 cases of intraductal carcinoma (Table 2). FDS confirmed 880 cases of non-elevated lesions, including 380 cases of duct dilation, 350 cases of duct inflammation, 136 cases of duct dilation and inflammation, and 14 cases of DCIS.

The pathological examinations confirmed 2,816 cases 



Figure 2 Pathological specimens and images by FDS. FDS, fiberoductoscopy.

Table 1 General information and clinical characteristics of FDS patients

\begin{tabular}{|c|c|c|c|c|}
\hline Item & $\begin{array}{l}\text { Elevated lesions } \\
\qquad(n=2,816)\end{array}$ & $\begin{array}{l}\text { Non-elevated } \\
\text { lesions }(n=880)\end{array}$ & $t / \chi^{2}$ & $P$ \\
\hline Age & $40.64 \pm 9.81$ & $40.58 \pm 9.83$ & 0.172 & 0.863 \\
\hline Age of onset & $14-89$ & $17-86$ & - & - \\
\hline \multicolumn{3}{|c|}{ Color of discharge } & 521.117 & $<0.001$ \\
\hline Colorless & 394 & 320 & & \\
\hline Yellow & 536 & 353 & & \\
\hline Red & 1,886 & 207 & & \\
\hline \multicolumn{3}{|c|}{ Properties of the discharge } & 925.554 & $<0.001$ \\
\hline Serous & 648 & 170 & & \\
\hline Mucinous & 282 & 502 & & \\
\hline Bloody & 1,886 & 208 & & \\
\hline \multicolumn{3}{|c|}{ Distributions of the lesions } & 0.473 & 0.492 \\
\hline Left & 1,391 & 423 & & \\
\hline Right & 1,425 & 457 & & \\
\hline \multicolumn{3}{|c|}{ Number of target ducts } & 1.300 & 0.254 \\
\hline 1 & 2,235 & 714 & & \\
\hline$\geq 2$ & 581 & 166 & & \\
\hline
\end{tabular}

FDS, fiberoductoscopy. of elevated lesions, including 1,942 cases of intraductal papilloma, 578 cases of intraductal papillomatosis, and 296 cases of intraductal carcinoma. The pathological examinations confirmed 880 cases of non-elevated lesions, including 379 cases of duct dilatation, 351 cases of duct inflammation, 136 cases of duct dilation and inflammation, and 14 cases of DCIS.

We compared the FDS and pathological diagnoses and found that for elevated intraductal lesions, FDS correctly confirmed $97.52 \%, 90.07 \%$, and $94.31 \%$ of the cases of intraductal papilloma, intraductal papillomatosis, and intraductal carcinoma, respectively (the kappa concordance indexes were $0.913,0.881$, and 0.942 , respectively; all $\mathrm{P}<0.001)$. For non-elevated intraductal lesions, FDS correctly confirmed $98.95 \%, 99.43 \%, 97.79 \%$, and $92.86 \%$ of the cases of duct dilation, duct inflammation, duct dilation and inflammation, and DCIS, respectively (the kappa concordance indexes were $0.984,0.988,0.974$, and 0.927 , respectively; all $\mathrm{P}<0.001$ ) (Tables 2,3 ).

All patients followed up 3 months to 12 years, averaging in 53 months, intraductal papilloma recurred in 68 cases, relapsed in 84 cases, papillomatosis (multiple papilloma) recurred in 30 cases, relapsed in 21 cases, duct dilation recurred in 18 cases, relapsed in 22 cases, inflammation recurred in 23 cases, relapsed in 12 cases. There were 241 DCIS in total, of which local recurrence occurred in 8 cases, distant metastasis was observed in 2 patients, and both cases had pulmonary metastasis. Invasive ductal carcinoma, 41 cases, recurring in 3 cases and 3 cases 
Table 2 FDS and pathological diagnoses of elevated lesions

\begin{tabular}{|c|c|c|c|c|c|c|c|c|c|}
\hline FDS diagnosis & Result & \multicolumn{2}{|c|}{ Pathological diagnosis } & Total & Sensitivity & Specificity & $\begin{array}{l}\text { Positive } \\
\text { predictive rate }\end{array}$ & $\begin{array}{c}\text { Kappa concordance } \\
\text { index }\end{array}$ & $P$ \\
\hline \multirow{3}{*}{$\begin{array}{l}\text { Intraductal } \\
\text { papilloma (type I) }\end{array}$} & Positive & 1,885 & 48 & 1,933 & $97.06 \%$ & $94.51 \%$ & $97.52 \%$ & 0.913 & $<0.001$ \\
\hline & Negative & 57 & 826 & 883 & & & & & \\
\hline & Total & 1,942 & 874 & 2,816 & & & & & \\
\hline \multirow{2}{*}{$\begin{array}{l}\text { Intraductal } \\
\text { papillomatosis } \\
\text { (type II) }\end{array}$} & Negative & 52 & 2,180 & 2,232 & & & & & \\
\hline & Total & 578 & 2,238 & 2,816 & & & & & \\
\hline \multirow{2}{*}{$\begin{array}{l}\text { Intraductal } \\
\text { carcinoma (type III) }\end{array}$} & Positive & 282 & 17 & 299 & $95.27 \%$ & $99.33 \%$ & $94.31 \%$ & 0.942 & $<0.001$ \\
\hline & Negative & 14 & 2,503 & & & & & & \\
\hline
\end{tabular}

FDS, fiberoductoscopy.

Table 3 FDS and pathological diagnoses of non-elevated lesions

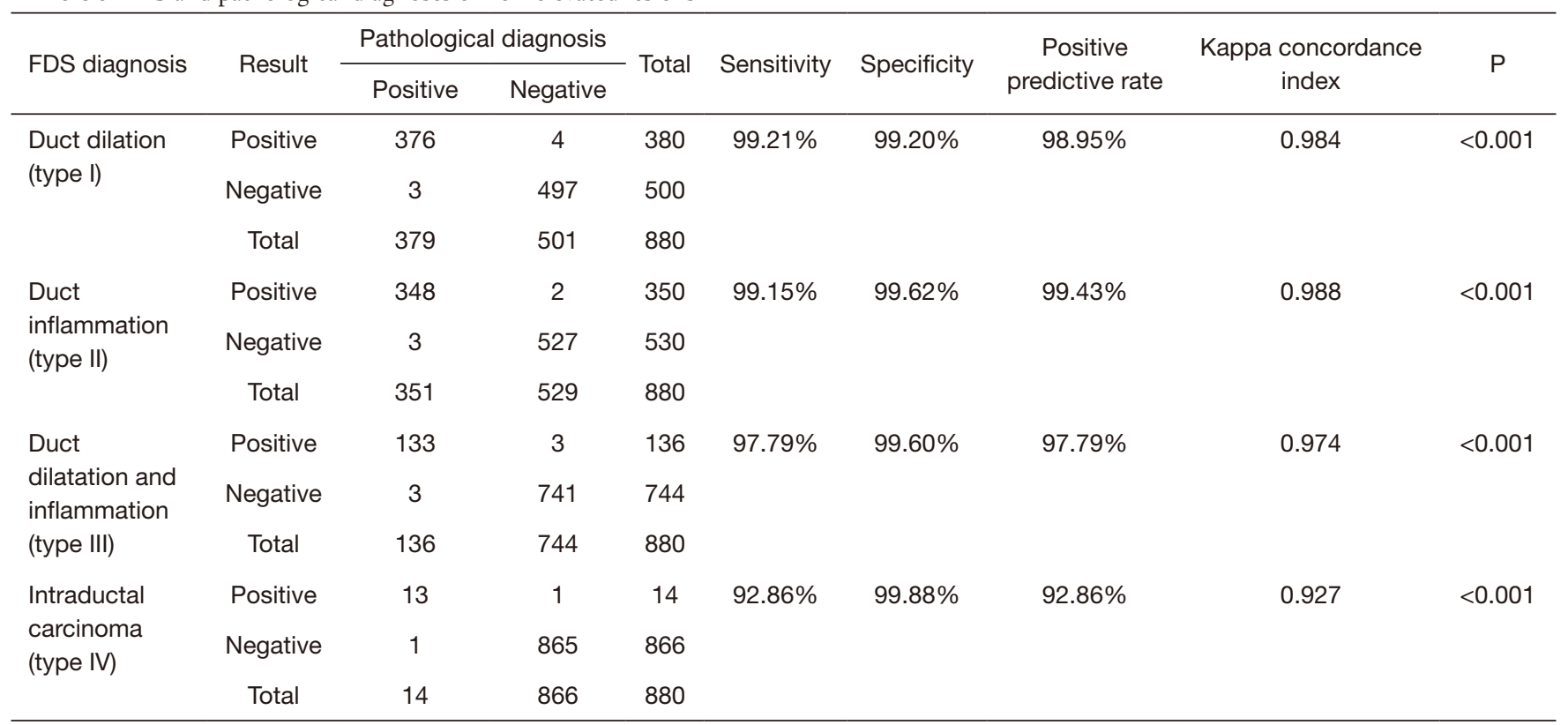

FDS, fiberoductoscopy.

occurred distant metastasis, 1 for bony, and 2 for pulmonary. One case died in this group. Invasive lobular carcinoma occurred in 23 cases, recurring 2 cases, and 1 case for bony metastasis. Five cases were reported as inflammatory breast cancer for 3 cases, 1 case for primary squamous cell carcinoma (PSCC), and 1 for primary mammary lymphoma. The PSCC case died after surgery for 3 years (Tables 4-7).

Risk and side effects of FDS includes: infection, failure of the operation, creating a false road, subcutaneous emphysema and minor pain when operation.

\section{Discussion}

No consensus has been achieved on standard detection methods for PND, and researchers are still debating the value of FDS. This study included 3,696 patients who underwent FDS and were diagnosed with the findings. The results showed a high correlation between the FDS and 
Table 4 Diagnosis by FDS $v s$. pathologic result of elevated lesion

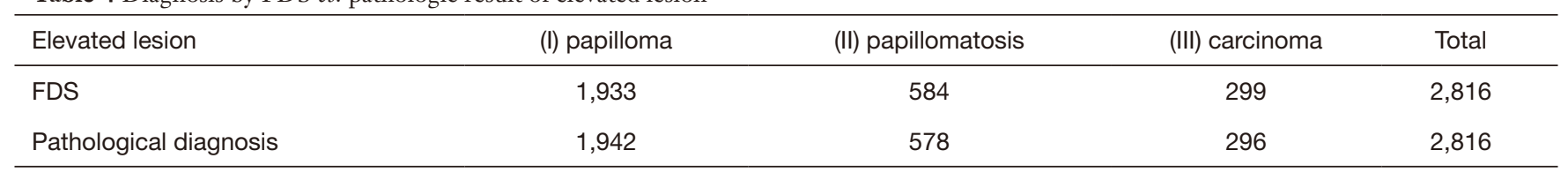

FDS, fiberoductoscopy.

Table 5 Diagnosis by FDS vs. pathologic result of non-elevated lesion

\begin{tabular}{lccccc}
\hline Non-elevated lesion & (I) dilation & (II) inflammation & (III) dilation and inflammation & (IV) carcinoma & Total \\
\hline FDS & 380 & 350 & 136 & 880 & 14 \\
Pathological diagnosis & - & - & - & 13 & 13 \\
\hline
\end{tabular}

FDS, fiberoductoscopy.

Table 6 Follow up of benign lesions

\begin{tabular}{lccc}
\hline Benign & Recurrence & Relapse & Total \\
\hline Papilloma & 68 & 84 & 152 \\
Papillomatosis & 30 & 21 & 51 \\
Dilation & 18 & 22 & 40 \\
Inflammation & 23 & 12 & 35 \\
\hline
\end{tabular}

Table 7 Follow up of malignant patients

\begin{tabular}{lcccc}
\hline $\begin{array}{l}\text { Malignant 310 } \\
\text { [14+296] }\end{array}$ & Surgery & Treatment & Recurrence & Metastasis \\
\hline DCIS [14+227] & Local extended resection 143; mastectomy 98 & Chemo 0; radio 143; endocrine 9 & 8 & 2 \\
$\begin{array}{l}\text { Invasive ductal } \\
\text { carcinoma [41] }\end{array}$ & Mastectomy 29; breast-conserving surgery 12 & Chemo 38; radio 1; endocrine 29 & 3 & 0 \\
$\begin{array}{l}\text { Invasive lobular } \\
\text { carcinoma [23] }\end{array}$ & Mastectomy 15; breast-conserving surgery 8 & Chemo 20; radio 0; endocrine 19 & 2 & 1 \\
Others [5] & Mastectomy 4; breast-conserving surgery 1 & Chemo 5; radio 0; endocrine 3 & 0 & 1 \\
\hline
\end{tabular}

pathological diagnoses, suggesting that FDS can diagnose intraductal lesions.

Many methods are available for detecting PND, but they all have certain limitations. Earlier studies have shown that radiologic imaging, including ductography and MRI, has a low sensitivity for detecting PND $(5,8,18,19)$. Researchers are still debating the value of cytological analysis of nipple secretions. Liu et al. (20) showed that cytological analysis performed with ductography somewhat improved the results of ductography, but Kooistra et al. (21) found that cytological analysis had little value. Some studies found there was no value in the cytological analysis of duct lavage fluids (22). The detection of serum protein markers or methylation in nipple secretions or duct lavage fluid is promising (23-28). Enhanced imaging techniques, including autofluorescence, may improve diagnostic accuracy $(29,30)$.

Table 2 includes distinct types of elevated lesions, including intraductal papilloma, intraductal papillomatosis, and intraductal carcinoma in situ. FDS correctly confirmed $97.52 \%$ of the intraductal papilloma cases, but only $90.07 \%$ 




Figure 3 Classify and management for PND patients by using FDS. PND, pathological nipple discharge; FDS, fiberoductoscopy.

of the intraductal papillomatosis cases. These results may be because the endoscope was advanced along the duct during FDS. If the top part of the elevated lesion was occluded entirely, then it was impossible to advance the endoscope across the lesion to observe the duct distal to the occlusion. If the top part occluded the central duct or duct bifurcation, then it was impossible to examine all the ducts distal to the occlusion. The phenomenon explains the FDS diagnosis of "papilloma" rather than "papillomatosis." Here, follow-up surgery should be slightly expanded to ensure the resection of all elevated lesions.

FDS correctly confirmed $94.31 \%$ of the cases of intraductal carcinoma, partly because of the prominent, easy-to-identify characteristics of the lesions, including (I) characteristics of a malignant tumor, including ill-defined edges, hard texture, and irregular or lobulated shape; (II) susceptibility to bleeding upon contact and breaking easily upon contact with the endoscope; (III) duct walls around the lesion that exhibit signs of "infiltration," including stiffness and low elasticity; and (IV) a lesion no longer confines to a single duct as it progresses, showing "external oppression" during FDS. Most of the suspected malignant lesions exhibit the first three or all four of the endoscopic signs described above, thus providing invaluable visual imaging evidence for the diagnosis of $\mathrm{T} 1$ or even $\mathrm{T} 0$ breast cancer with "nipple discharge" as its initial symptom. The diagnostic rate of the malignant lesions may have been further improved if high-resolution techniques, including MRI, were also performed. Reduce missed diagnosis is also the direction of our effort. Although MRI cost expensive in China, some PND patients should be better to do MRI to help diagnose before surgery (31).

Table 3 shows that for the non-elevated lesions, FDS correctly confirmed $92.86 \%$ of the intraductal carcinoma cases. These lesions showed no evident intraductal elevation, but the duct walls were inelastic, stiff, prone to bleeding, and sometimes "externally oppressed." These characteristics showed malignant lesions.

Figure 3 shows the standard FDS procedure and process for PND patients while setting up unified terms for lesion descriptions. The report should include (I) the location of the duct with discharge (o'clock); (II) the distance between the duct with discharge and the central duct, and the number of ducts with discharge; (III) the direction and location of the endoscope (o'clock); (IV) the depth of the endoscope and the distance between the lesion and the nipple; and $(\mathrm{V})$ a description of the duct branches starting from the central duct and including intraductal fluid retention, a tumor and a description of the tumor (if applicable), and the ductal wall.

FDS aids in setting up and ensuring a standardized diagnosis and treatment process for PND patients and 
prevents unnecessary surgery (32). Standardized imaging and reporting systems help physicians with no access to FDS for finding the lesion location, reduce surgery, and improve the accuracy of lesion resection. For PND patients, FDS-aided diagnosis and treatment have practical value. First, FDS enables visual description and classification of intraductal lesions and supplies a reference for pathological examinations. Second, FDS helps locate intraductal lesions, thus reducing surgery and aiding pathologists in the identification of micro-lesions. Third, FDS improves surgical indications for breast disease, ending the need for surgery in some patients.

In order to reduce the loss of follow-up rate in this large sample study for a long time, we have two important approaches: one is at the first visit of PND patients, we did emphasize the importance of follow-up, and the other one is Combining online and offline follow-up, using WeChat app to remind patients and responsible doctor for follow-up regularly.

\section{Conclusions}

This study shows the value of FDS for patients with PND. Patients with intraductal inflammation or hyperplasia no longer need to undergo surgery, and surgery can be reduced in patients with benign intraductal lesions. Patients with early stage malignant tumors may be diagnosed and treated promptly, thus improving the chance of breast-preserving radical mastectomy $(33,34)$, helping reduce patient discomfort and preserve breast appearance.

\section{Acknowledgments}

Funding: None.

\section{Footnote}

Reporting Checklist: The authors have completed the STROBE reporting checklist. Available at http://dx.doi. org/10.21037/gs-20-738

Data Sharing Statement: Available at http://dx.doi. org/10.21037/gs-20-738

Conflicts of Interest: All authors have completed the ICMJE uniform disclosure form (available at http://dx.doi. org/10.21037/gs-20-738). The authors have no conflicts of interest to declare.
Ethical Statement: The authors are accountable for all aspects of the work in ensuring that questions related to the accuracy or integrity of any part of the work are appropriately investigated and resolved. An in-depth discussion about the risks and benefits of the procedure was followed by obtaining informed written consent for patients to undergo FDS. All patients agreed to follow the study schedule and undergo biopsies after FDS. The Ethical Committees approved this project of Beijing Chaoyang Hospital. The study conformed to the provisions of the Declaration of Helsinki (as revised in 2013).

Open Access Statement: This is an Open Access article distributed in accordance with the Creative Commons Attribution-NonCommercial-NoDerivs 4.0 International License (CC BY-NC-ND 4.0), which permits the noncommercial replication and distribution of the article with the strict proviso that no changes or edits are made and the original work is properly cited (including links to both the formal publication through the relevant DOI and the license). See: https://creativecommons.org/licenses/by-nc-nd/4.0/.

\section{References}

1. Chen $\mathrm{W}$, Zheng R, Baade PD, et al. Cancer statistics in China, 2015. CA Cancer J Clin 2016;66:115-32.

2. Stone K, Wheeler A. A Review of Anatomy, Physiology, and Benign Pathology of the Nipple. Ann Surg Oncol 2015;22:3236-40.

3. Patel BK, Falcon S, Drukteinis J. Management of Nipple Discharge and the Associated Imaging Findings. Am J Med 2015;128:353-60.

4. Montroni I, Santini D, Zucchini G, et al. Nipple discharge: is its significance as a risk factor for breast cancer fully understood? Observational study including 915 consecutive patients who underwent selective duct excision. Breast Cancer Res Treat 2010;123:895-900.

5. Hao N, Yuan X, Wang Q, et al. The role of magnetic resonance imaging in detection and surgical treatment of breast intraductal papillomas. Transl Cancer Res 2019;8:635-46.

6. Mokbel K, Elkak A. The evolving role of mammary ductoscopy. Curr Med Res Opin 2002;18:30-2.

7. Okazaki A, Okazaki M, Asaishi K, et al. Fiberoptic ductoscopy of the breast: a new diagnostic procedure for nipple discharge. Jpn J Clin Oncol 1991;21:188-93.

8. Dawes LG, Bowen C, Venta LA, et al. Ductography for nipple discharge: no replacement for ductal excision. 
Surgery 1998;124:685-91.

9. Simmons R, Adamovich T, Brennan M, et al. Nonsurgical evaluation of pathologic nipple discharge. Ann Surg Oncol 2003;10:113-6.

10. Sharma R, Dietz J, Wright H, et al. Comparative analysis of minimally invasive microductectomy versus major duct excision in patients with pathologic nipple discharge. Surgery 2005;138:591-6; discussion 596-7.

11. Teboul M. A new concept in breast investigation: echohistological acino-ductal analysis or analytic echography. Biomed Pharmacother 1988;42:289-95.

12. Makita M, Akiyama F, Gomi N, et al. Endoscopic and histologic findings of intraductal lesions presenting with nipple discharge. Breast J 2006;12:S210-S217.

13. Denewer A, El-Etribi K, Nada N, et al. The role and limitations of mammary ductoscope in management of pathologic nipple discharge. Breast J 2008;14:442-9.

14. Louie LD, Crowe JP, Dawson AE, et al. Identification of breast cancer in patients with pathologic nipple discharge: does ductoscopy predict malignancy? Am J Surg 2006;192:530-3.

15. Dietz JR, Crowe JP, Grundfest S, et al. Directed duct excision by using mammary ductoscopy in patients with pathologic nipple discharge. Surgery 2002;132:582-7; discussion 587-8.

16. Kamali S, Bender O, Aydin MT, et al. Ductoscopy in the evaluation and management of nipple discharge. Ann Surg Oncol 2010;17:778-83.

17. Jiang HC. Duct lesion map under fiberoptic duct endoscopy. Hong Kong: Hong Kong Pharmaceutical Publishing House, 2003

18. Vaughan A, Crowe JP, Brainard J, et al. Mammary ductoscopy and ductal washings for the evaluation of patients with pathologic nipple discharge. Breast J 2009;15:254-60.

19. Sarica O, Ozturk E, Demirkurek HC, et al. Comparison of ductoscopy, galactography, and imaging modalities for the evaluation of intraductal lesions: a critical review. Breast Care (Basel) 2013;8:348-54.

20. Liu GY, Lu JS, Shen KW, et al. Fiberoptic ductoscopy combined with cytology testing in the patients of spontaneous nipple discharge. Breast Cancer Res Treat 2008;108:271-7.

21. Kooistra BW, Wauters C, van de Ven S, et al. The diagnostic value of nipple discharge cytology in 618 consecutive patients. Eur J Surg Oncol 2009;35:573-7.

22. Loud JT, Thiébbaut AC, Abati AD, et al. Ductal lavage in women from BRCA1/2 families: is there a future for ductal lavage in women at increased genetic risk of breast cancer? Cancer Epidemiol Biomarkers Prev 2009;18:1243-51.

23. Fackler MJ, Rivers A, Teo WW, et al. Hypermethylated genes as biomarkers of cancer in women with pathologic nipple discharge. Clin Cancer Res 2009;15:3802-11.

24. Antill YC, Mitchell G, Johnson SA, et al. Gene methylation in breast ductal fluid from BRCA1 and BRCA2 mutation carriers. Cancer Epidemiol Biomarkers Prev 2010;19:265-74.

25. Suijkerbuijk KPM, van derWall E, Vooijs M, et al. Molecular analysis of nipple fluid for breast cancer screening. Pathobiology 2008;75:149-52.

26. de Noo ME, Deelder A, van derWerff M, et al. MALDITOF serum protein profiling for the detection of breast cancer. Onkologie 2006;29:501-6.

27. Mertens BJ, De Noo ME, Tollenaar RA, et al. Mass spectrometry proteomic diagnosis: enacting the double crossvalidatory paradigm. J Comput Biol 2006;13:1591-605.

28. Suijkerbuijk KP, van Diest PJ, van derWall E. Improving early breast cancer detection: focus on methylation. Ann Oncol 2011;22:24-9.

29. Jacobs VR, Paepke S, Schaaf H, et al. Autofluorescence ductoscopy: a new imaging technique for intraductal breast endoscopy. Clin Breast Cancer 2007;7:619-23.

30. Douplik A, Leong WL, Easson AM, et al. Feasibility study of autofluorescence mammary ductoscopy. J Biomed Opt 2009; 14:044036.

31. Kamali S, Bender O, Kamali GH, et al. Diagnostic and therapeutic value of ductoscopy in nipple discharge and intraductal proliferations compared with standard methods. Breast Cancer 2014;21:154-61.

32. Zervoudis S, Iatrakis G, Economides P, et al. Nipple discharge screening. Womens Health (Lond) 2010;6:135-51.

33. Dooley WC. Breast ductoscopy and the evolution of the intra-ductal approach to breast cancer. Breast J 2009;15 Suppl 1:S90-4.

34. Zervoudis S, Tamer V, Iatrakis G, et al. Improving ductoscopy with duct lavage and duct brushing. Eur J Gynaecol Oncol 2014;35:548-53.

(English Language Editor: J. Chapnick)

Cite this article as: Zhang C, Li J, Jiang H, Li M. Use of fiberoductoscopy for the management of pathological nipple discharge: ten years follow up of a single center in China. Gland Surg 2020;9(6):2035-2043. doi: 10.21037/gs-20-738 